\section{Intervención en la muralla de La Hoya de Almería}

En breve finalizarán las obras de intervención en la muralla de la Hoya de la ciudad de Almería. Se trata de una restauración controvertida que ha suscitado un debate sobre la idoneidad de los criterios utilizados en la restauración de la misma. Tras una fase de diagnóstico se decidió actuar de manera urgente para dar solución a los graves problemas en el inmueble referidos principalmente a la consolidación de fábricas y revestimientos, y a la eliminación de humedades.
Este último capítulo se reveló como una de las principales causas de patologias en un edificio construido originalmente en tapial; un material constituido por tierra apisonada y cohesionada, con aportes de cal más o menos homogéneos, y mejorado en las superficies exteriores con una costra de mortero más rico en ésta que actúa como piel protectora de la fábrica. Cuando el agua llega al corazón del tapial, bien por

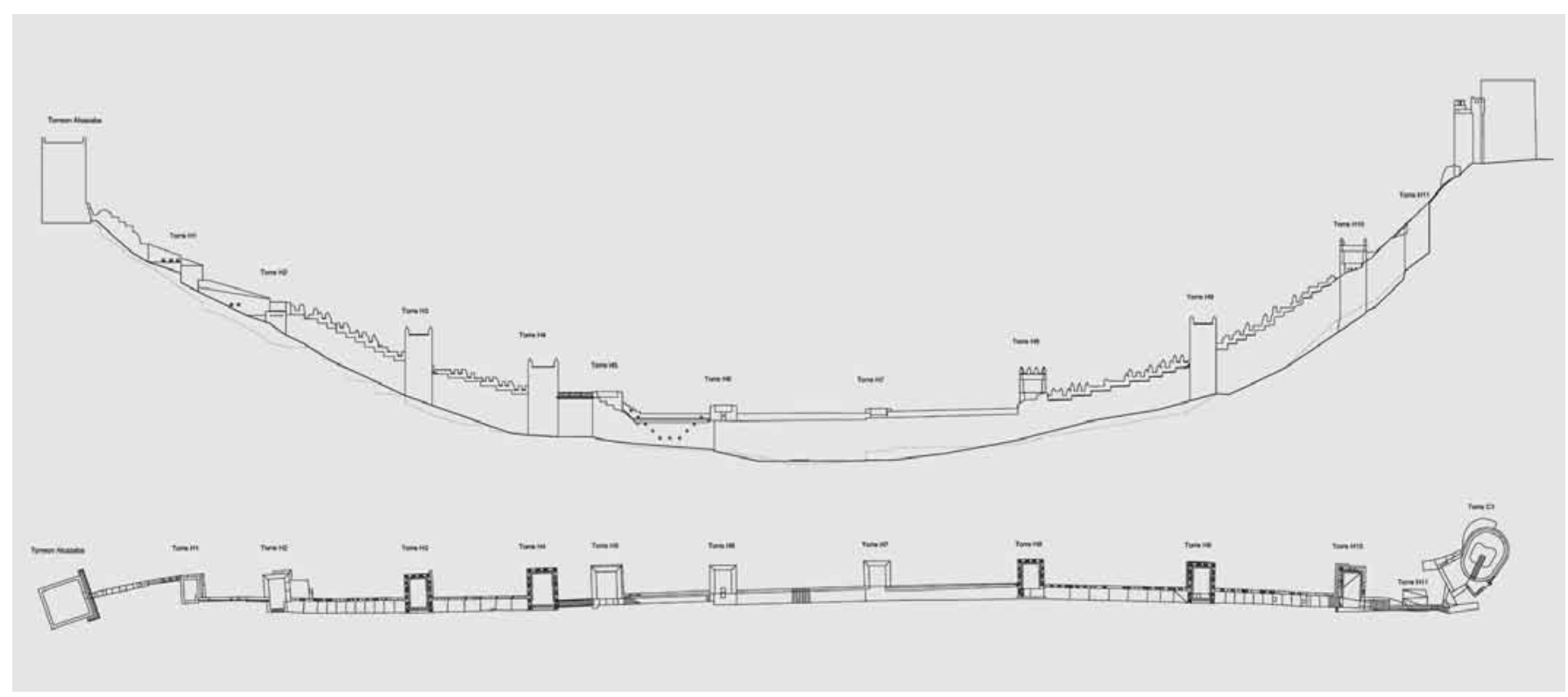

Levantamiento del desarrollo completo de la muralla de la Hoya: planta y alzado sureste. Para la localización de las distintas partes se emplea la nomenclatura de la ficha diagnóstico, que identifica las torres como $\mathrm{Hl}, \ldots \mathrm{Hl} 1$, siendo la primera la más próxima a la Alcazaba y la última la más próxima al cerro de San Cristóbal, mientras que los tramos de muro se nombran con las dos torres entre las que se encuentran. Plano: Jesús $M$. Basterra Pinilla

\section{Las humedades se \\ revelaron como una de las principales causas de patologías en un edificio construido originalmente con tapial}

La muralla de la Hoya es una construcción de época califal (s. XI) iniciada probablemente en tiempos de Jairán. El tramo de la Hoya es una continuación de la muralla del cerro de San Cristóbal, formando ambos, junto a la propia Alcazaba, un conjunto de indudable importancia para el patrimonio histórico almeriense y andaluz.

La intervención tomó como punto de partida los criterios establecidos en la ficha diagnóstico y ha dado respuesta a las necesidades más urgentes del monumento que inicialmente se identificaron, ratificadas durante la fase de proyecto y obra, consistentes en limpieza general, consolidación puntual en fábricas y revestimientos, y eliminación de humedades. infiltración o bien por capilaridad o condensaciones internas, se inicia un lento pero inexorable proceso de disolución de la fábrica que ve disminuidas progresivamente sus cualidades resistentes, lo que unido a las periódicas oscilaciones térmicas acaba manifestándose primero en fisuras y luego en grietas, las cuales favorecen más aportes hídricos, dando lugar a un ciclo que acelera el proceso destructivo y la ruina del edificio.

Atendiendo a tal circunstancia, para garantizar la correcta supresión de humedades y evitar sus efectos nocivos, se ha diversificado la actuación, a su vez, en otros tres apartados distintos, a saber: drenaje del terreno próximo a la cimentación, establecimiento de una barrera contra su ascenso por capi- 
laridad, e impermeabilización de paramentos y superficies horizontales.

El terreno era una fuente importante de agua debido a la propia orografía del entorno. La muralla atraviesa transversalmente una vaguada -prolongación de la actual calle de la Reina- entre el cerro de la Alcazaba y el de San Cristóbal, donde se recoge la escorrentía de Iluvia, afectando directamente a la parte central del monumento, que debía tener -como asi fueunos orificios de paso a través del muro. Se protegió la cimentación con sendas líneas de drenaje, una por la cara noroeste (cara exterior de la muralla, aguas arriba) y otra por la sureste (cara interior, aguas abajo), hasta que la roca de las laderas impidió la continuación de las zanjas. Varias arquetas registrables permiten comprobar la recogida y facilitan la conexión de ambas líneas aprovechando la existencia de los aliviaderos originales, la cual se presumía y fue confirmada tras las labores de desbroce y limpieza. La idea inicial era simplemente documentarlos y aprovecharlos para pasar la canalización, pero su aspecto, a pesar de haber estado protegidos por el terreno, hizo pensar en una intervención de más alcance que no estaba prevista. Todos los trabajos de drenaje se realizaron, lógicamente, bajo supervisión arqueológica y ello permitió documentar diversos restos de cerámica, construcciones adosadas a la muralla y varios bolaños de piedra, probablemente de catapulta, enterrados en el sedimento de las cotas más bajas.

La siguiente actuación contra las humedades se localizó en la base del muro, por encima de la rasante del terreno. Se trataba de establecer una barrera contra el ascenso por capilaridad, para lo que se recurrió a una línea de higroconvectores por cada cara. Cada uno de estos elementos consiste en un cuerpo de cerámica hidrófila muy porosa que se empotra en la fábrica, dándole una pendiente del 15\% descendente hacia afuera, de forma que el aire contenido cede calor para la evaporación al entrar en contacto con el agua, se enfria y aumenta su densidad, descendiendo hacia fuera por la parte inferior del tubo y permitiendo la entrada de aire cálido más ligero por la parte alta. Este proceso se produce de forma lenta pero constante reduciendo progresivamente la humedad interior sin disolver el tapial. El sistema es válido tanto para detener el ascenso por capilaridad como para evacuar el vapor de agua intersticial y corregir la humedad de condensación interna que origina. En el conjunto de la muralla se han colocado más de mil higroconvectores, a razón de tres unidades por metro lineal, concentrándolos en las partes más bajas donde existe contacto con el terreno sedimentario.

Para evitar la entrada de agua por infiltración fue necesario consolidar y sellar numerosas grietas y pérdidas de materia, tanto en adarves como en paramentos. Sólo en la gran fractura existente en el adarve en las inmediaciones de las torres H7, H8 y H9 se emplearon más de $2 \mathrm{~m}^{3}$ de lechada de mortero de cal que fue progresivamente vertida con el doble objetivo de cohesionar y sellar el núcleo de tapial. En paramentos era frecuente encontrar ejemplos de las diferentes etapas del deterioro de éste, desde la reciente pérdida de la piel

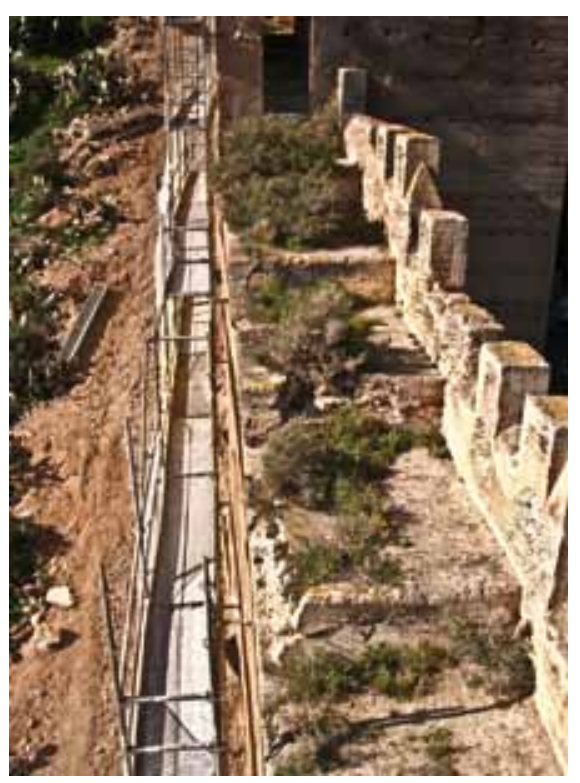

Estado anterior y posterior a la intervención en el adarve escalonado $(\mathrm{H} 3 \mathrm{H} 4$ y $\mathrm{H} 2 \mathrm{H} 3)$. Fotos: José Lobo Rull y José M. Parra Córdoba

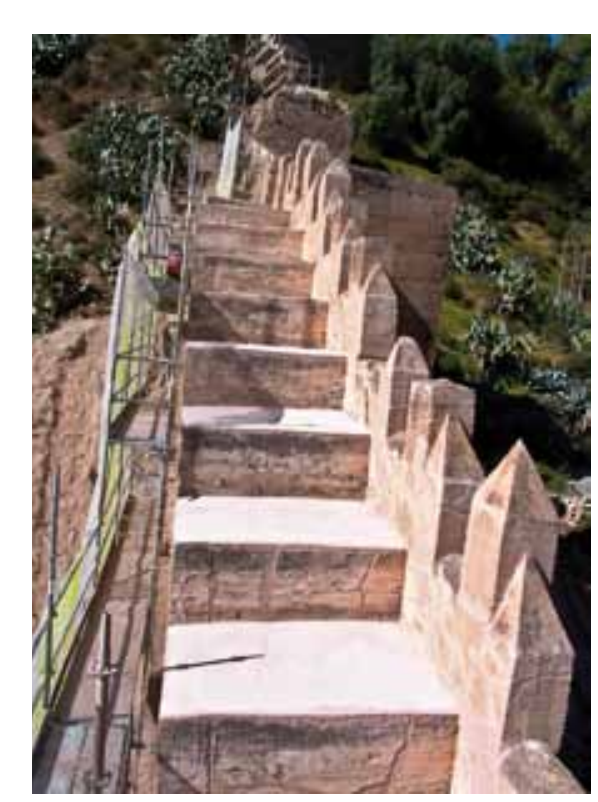

protectora, casi exclusivamente a nivel de revestimientos, hasta casos en los que la disolución de la tierra de la parte central había producido cavidades de magnitud considerable sólo protegidas parcialmente por la cáscara exterior rica en cal. Cada caso se trató en función de sus necesidades, rellenando con mortero las pérdidas principales y reforzando con mineralizador las superficies externas que presentaban riesgo de disgregación.

El conjunto de adarves y paramentos de la muralla quedó convenientemente protegido con estas actuaciones, pero las torres mostraban las patologias adicionales de unos muros que habian perdido los forjados intermedios y presentaban la mayor concentración de grietas, fracturas, pérdidas de material y desplomes, agravado en gran parte por su esbeltez. Inicialmente sólo se preveía trabar cubriendo a nivel de lo que fue la cubierta original, pero la observación detenida y cercana de los daños aconsejó no sólo realizar un atado a mitad de su elevación sino, además, aportar una ligera estructura centradora en las torres $\mathrm{H} 8$ y $\mathrm{H} 10$ donde se habian perdido completamente las paredes surestes $y$, parcialmente, los paramentos adyacentes a éstas. Dicha 


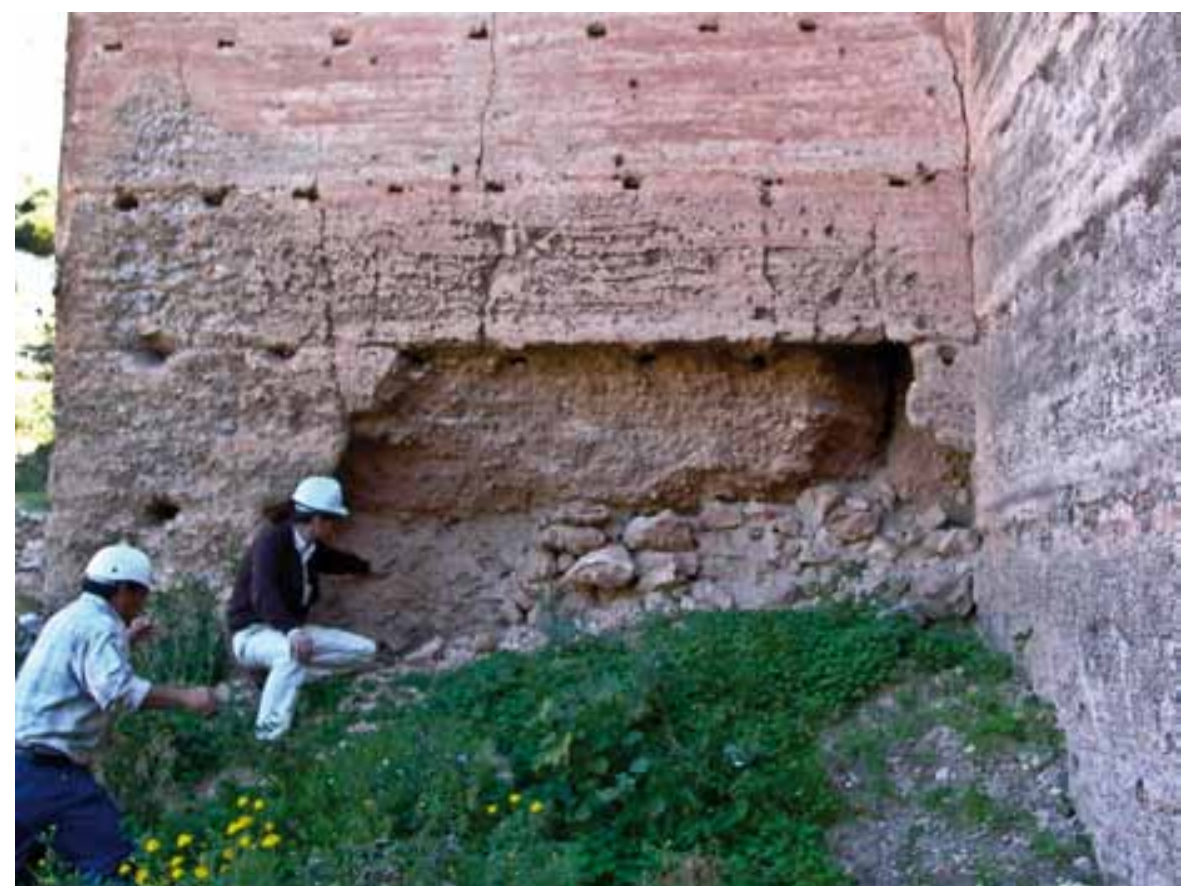

Pérdida de material por disolución de tapial en las proximidades al terreno $(\mathrm{H} 8)$

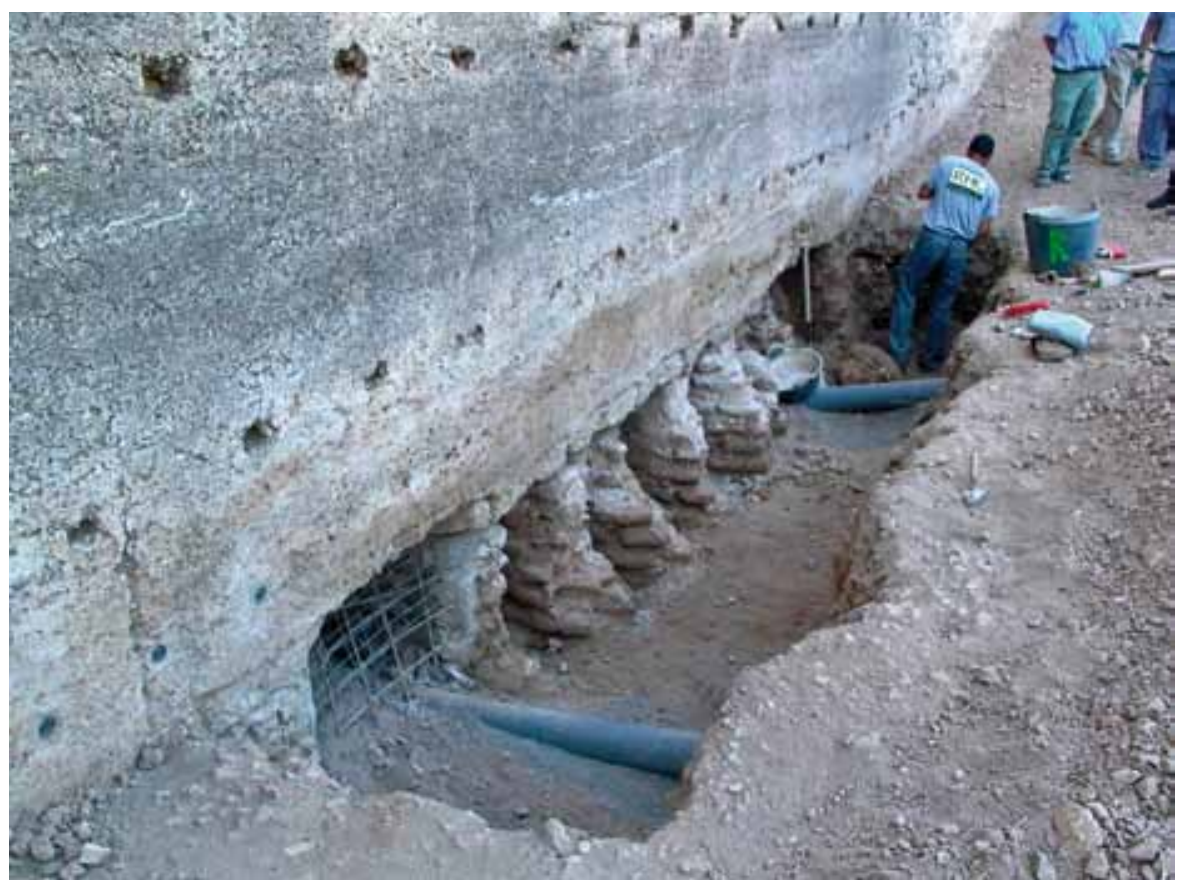

Obras de recuperación de los aliviaderos de escorrentías en la base del monumento (H6H7)
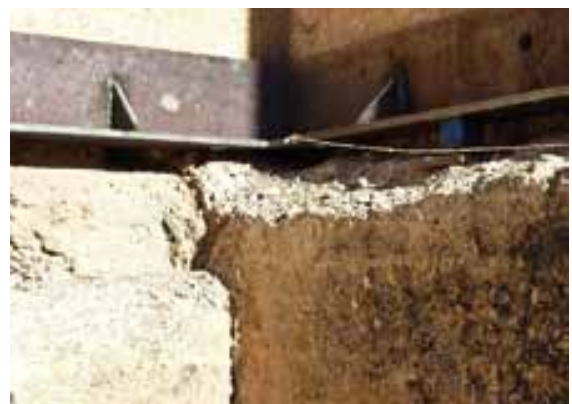

Detalle del zuncho de atado de los muros

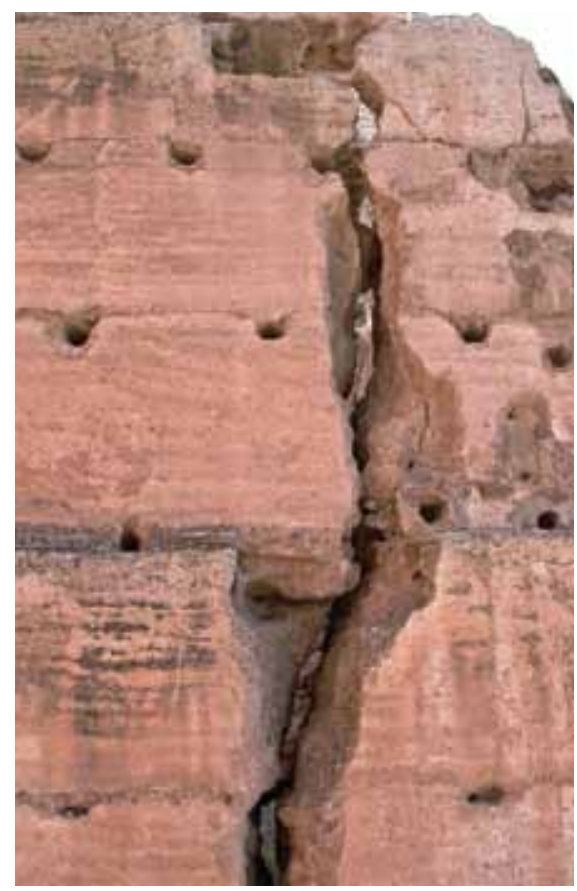

Grieta de fractura cuya magnitud deja ver el intradós (H10)

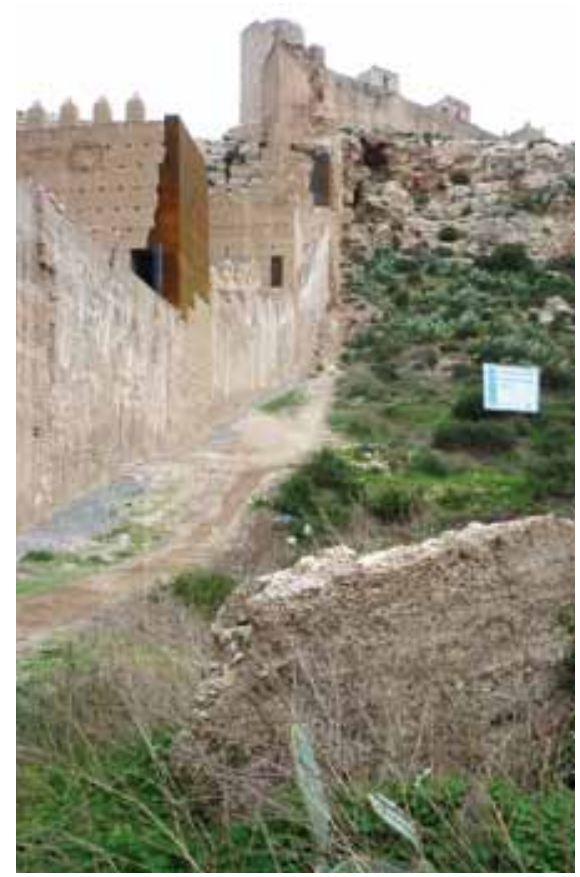

Vista general (desde H7), mostrando los refuerzos estructurales $(\mathrm{H} 8$ y $\mathrm{H} 10)$

La colocación del armazón metálico ha llevado a confusión a un cierto sector de opinión que lo ha interpretado como una pretendida restitución formal 
intervención se hizo necesaria para asegurar a medio plazo la pervivencia de las dos torres. Hay que tener en cuenta que la mayoria de ellas no conserva su volumen por encima de la cota del adarve, y en $\mathrm{H} 3$ y $\mathrm{H} 4$ existen precedentes de refuerzos estructurales de envergadura que se remontan a las décadas de los 60 y 70 del siglo pasado, cuando la ruina de paramentos obligó a consolidar gran parte de estos elementos con hormigón. Sólo la torre H9 conserva aún todo su perimetro de tapial a pesar de los signos de deterioro que muestra. Así pues, a partir de lo expuesto, se decidió que la sujeción y equilibrado de la estructura se ejecutara con un liviano entramado metálico apoyado y/o atornillado en la fábrica original.

El acabado en chapa de acero Corten evidencia que es una intervención actual que no pretende pasar por original, en línea con la ortodoxia en restauración de inmuebles. Dicho material se clasifica como acero resistente a la corrosión atmosférica y una de sus cualidades más apreciadas es que no precisa mantenimiento; el propio material se autoprotege creando una pátina que es sumamente densa y adherente, preserva eficazmente del ataque de la corrosión y paraliza su progresión. Su uso es frecuente en actuaciones sobre patrimonio, incluso en las proximidades del mar, el riesgo de manchas es bajo -se produce sólo en la fase inicial de formación de la pátina- $y$, en cualquier caso, pueden eliminarse completamente con el tratamiento adecuado.

La simplicidad formal de las torres ha dado como resultado una aparente reposición volumétrica de las mismas debido a la colocación del armazón metálico en el único lugar posible, es decir, donde faltaba el paramento, lo que ha llevado a confusión a un cierto sector de opinión que lo ha interpretado como una pretendida restitución formal, algo muy distinto de su verdadero objetivo: se trata sólo del resultado estructural necesario para la ade- cuada distribución simétrica de los esfuerzos del conjunto de cada torre. Por tanto, hay que desechar la idea de una supuesta reconstrucción, considerando así algo que no es más que un refuerzo, un apeo que se limita a evitar el colapso de unos muros que habían perdido su monolitismo y arriostramiento.

Al hilo de lo anterior, también resulta conveniente aclarar algunas otras interpretaciones erróneas que se han podido difundir. La primera se refiere a las dudas suscitadas sobre la reversibilidad de esta última operación, algo que está plenamente garantizado por la sujeción roscada de la estructura metálica y por la ausencia de zunchos de hormigón. La segunda alude a los criterios de conservación establecidos en el artículo 20 de la Ley 14/2007, del Patrimonio Histórico de Andalucia, y, en especial, en su punto 4 -precisamente el de carácter específico para inmuebles-, con frecuencia omitido en debates más bien centrados en cuestiones genéricas aplicables a todo tipo de bienes y que pasan por alto el factor téctónico estructural de los edificios, como si en un debate técnico-científico pudiera prescindirse de los efectos derivados de la fuerza de la gravedad. Finalmente existe el equívoco de identificar la parte con el todo, haciendo extensivo dicho refuerzo, ejecutado en dos puntos muy concretos, al conjunto de la muralla, argumentando además que perjudicaba su lectura, cuando la intervención está permitiendo precisamente sostener y explicar dos de las últimas torres que se mantienen en pie: de las once originales sólo cinco conservan hoy su silueta, dos de ellas reforzadas en hormigón, otras dos en metal, y sólo una conservando sus cuatro paramentos. No es necesario incidir en que nuevas pérdidas supondrian un perjuicio irreversible en el perfil del monumento.

Finalmente, y dado su notable carácter documental, es oportuno reseñar que se ha optado por desbrozar, limpiar y consolidar el paso de agua original que atravesaba el muro, conformando en el terreno las embocaduras necesarias para encauzar y dirigir hacia él las eventuales aguas superficiales. De esta forma se pone de nuevo en servicio el desagüe restituyéndole su función original, y a la vez queda a la vista como elemento singular del lienzo. A petición del CSIC, ha sido preciso proteger los pasos con rejas para evitar el acceso de animales oportunistas hacia la Estación Experimental de Zonas Áridas, emplazada a poca distancia de este lugar.

Como dato curioso, las obras están permitiendo, además, documentar tres fechas grabadas en la superficie de la muralla, que indican probablemente momentos en los que se llevaron a cabo distintas obras de reparación: "Año 1773", "Día $1^{\circ}$ de Dicienbre de 1836", y una tercera más confusa "172?" o "192?".

A modo de conclusión hay que reseñar que las obras que finalizarán en breve suponen probablemente la intervención general más ambiciosa en siglos, en orden de limpiar, impermeabilizar y consolidar la muralla de la Hoya para garantizar la contención de un proceso de deterioro que aceleraba su ruina.

El equipo técnico de redacción y dirección de esta brillante actuación, amparada en rigurosos criterios arquitectónicos, está formado por el arquitecto Jesús M. Basterra Pinilla -también ganador del Concurso Nacional de Ideas para la Ordenación de San Cristóbal en 1999, convocado por la Consejería de Obras Públicas y Transportes de la Junta de Andalucia- y el arquitecto técnico José M. Lobo. Los trabajos dieron comienzo en 2008, estando a cargo de la UTE Rehabitec-Jarquil. La inversión total aproximada asciende a unos $700.000 €$.

\section{Emilio Cachorro Fernández}

Arquitecto, Universidad de Granada 